This is the peer reviewed post-print version of the following article: Al-Dulaymi, M., and El-Aneed, A. (2017) Tandem mass spectrometric analysis of novel peptide-modified gemini surfactants used as gene delivery vectors. J. Mass Spectrom., 52: 353-366, which has been published in final form at doi: $10.1002 /$ jms.3933. This article may be used for non-commercial purposes in accordance with Wiley Terms and Conditions for Self-Archiving.

\title{
Tandem Mass Spectrometric Analysis of Novel Peptide-Modified Gemini Surfactants Used as Gene Delivery Vectors.
}

Mays Al-Dulaymi ${ }^{1}$, Anas El-Aneed ${ }^{1 *}$

1. College of Pharmacy and Nutrition, University of Saskatchewan, Saskatoon, SK, Canada.

* To whom correspondence should be addressed: Anas El-Aneed, College of Pharmacy and Nutrition, University of Saskatchewan, 107 Wiggins Road, Room 3D01.3, Saskatoon, SK S7N 5E5, Canada. Phone: +1-306-966-2013, email: anas.el-aneed@usask.ca

\begin{abstract}
Diquaternary ammonium gemini Surfactants have emerged as effective gene delivery vectors. A novel series of eleven peptide-modified compounds was synthesized, showing promising results in delivering genetic materials. The purpose of this work is to elucidate the tandem mass spectrometric (MS/MS) dissociation behaviour of these novel molecules establishing a generalized MS/MS fingerprint.

Exact mass measurements were achieved using a hybrid quadrupole orthogonal time-offlight mass spectrometer (QqToF-MS) and a multi-stage tandem mass spectrometric analysis was conducted using a triple quadrupole-linear ion trap mass spectrometer (QqQLIT-MS). Both instruments were operated in the positive ionization mode and are equipped with electrospray ionization (ESI). Abundant triply charged $[\mathrm{M}+\mathrm{H}]^{3+}$ species were observed in the single stage analysis of all the evaluated compounds with mass accuracies of less than $8 \mathrm{ppm}$ in mass error. MS/MS analysis showed that the evaluated gemini surfactants exhibited peptide-related dissociation characteristics due to the presence of amino acids within the compounds' spacer region. In particular, diagnostic product ions were originated from the neutral loss of ammonia from the amino acids' side chain resulting in the formation of pipecolic acid at the N-terminus part of the gemini surfactants. In addition, a charge directed amide bond cleavage was initiated by the amino acids' side chain producing a protonated $\alpha$-amino- $\varepsilon$-caprolactam ion and its complimentary c-terminus ion that contains quaternary amines. MS/MS and $\mathrm{MS}^{3}$ analysis revealed common fragmentation behaviour among all tested compounds, resulting in the production of a universal MS/MS fragmentation pathway.
\end{abstract}

\section{Introduction}

Gene therapy has emerged as a promising therapeutic approach for the treatment of inherited and acquired genetic disorders. The last few decades have witnessed unprecedented interest in developing efficient vectors able to compact, protect and deliver genetic material into targeted cells $[1,2]$. One particular group is diquaternary ammonium gemini surfactants that have been extensively used as non-viral gene delivery vectors [3]. They have the ability to package and compact the negatively charged nucleic acids through electrostatic and hydrophobic interactions forming nano-sized lipoplexes [4]. Gemini surfactants are composed of two ionic head groups attached to their hydrocarbon tails and connected by a spacer (Figure 1A) [5]. The 
unique structure of gemini surfactants resulted in superior characteristics compared to their monomeric counterparts, such as their greater ability in reducing surface tension, lower critical micelle concentration (CMC) and lower Krafft temperature (critical micelle temperature) [6]. Owing to these enhanced characteristics, lower concentration of gemini surfactants are required for gene delivery compared to their monomeric counterparts, thus, they possess lower cytotoxicity profile [4]. In addition, gemini surfactants' distinctive structure offers various possibilities for structural modification, allowing for the production of compounds specifically designed to overcome delivery barriers. For example, the insertion of $\mathrm{pH}$-sensitive moieties resulted in the production of "intelligent" delivery vehicles that respond to the surrounding stimuli [7].

The most widely used group of gemini surfactants is the cationic $\mathrm{N}, \mathrm{N}$ bis(dimethylalkyl)- $\alpha, \omega$-alkane-diammonium surfactants (Figure 1). They were successfully utilized in delivering genetic materials both in vitro and in vivo [8, 9]. In fact, Badea et al. reported three-fold increase in topical transgene expression in animals treated with N,N'bis(dimethylhexadecyl)-1,3-propanediammonium dibromide (designated as 16-3-16) gemini surfactant-based nanoparticles compared to animals treated with naked DNA [9]. Despite the success of the traditional gemini surfactants, concerns regarding their toxicity have arisen [10]. Several approaches have been undertaken to address this problem, including the insertion of biocompatible and biodegradable moieties such as sugars, lipids, and amino acids [11-13]. For example, glycyl-lysine substituted gemini surfactants exhibited significantly higher gene expression in vitro and lower cytotoxicity compared to the unsubstituted parent compound [1416]. Moreover, in vivo topical application of the glycyl-lysine substituted gemini surfactantbased lipoplexes into the rabbit vaginal cavities demonstrated higher transgene efficiency compared to the parent compound without visible toxicity [17].

Although extensive research was focused on the design of new gemini surfactants and optimizing their physicochemical properties to increase efficiency and reduce side effects ${ }^{[3,16 \text {, }}$ ${ }^{18]}$, little is known about their post transfection fate. Many questions remain unanswered regarding the degradation profile of nanoparticles after releasing their therapeutic cargo including the formation of metabolic by-products, some of which can theoretically be toxic. Correlating the biodistribution and the biological fate of the nanoparticles to their chemical structure and physicochemical properties can provide insights into the rational design process to produce gene carriers with higher efficiency and reduced toxicity. Such knowledge will bridge the gap between empirical and rational design. As such, there is a need to develop analytical techniques that could identify and quantify gemini surfactants within complex biological samples.

Mass spectrometry (MS) is routinely used for both the quantitative and qualitative analysis of pharmaceuticals [19-22]. In our group, we investigated the fragmentation pathways of different structural families of gemini surfactants establishing collision induced dissociationtandem mass spectrometric (CID-MS/MS) fingerprints for accurate identification of gemini surfactants [23-26]. This data was subsequently utilized to develop MS-based methods for the quantification of conventional un-substituted gemini surfactants within cells to determine the rate of cellular uptake and removal [27-29]. Ongoing research employs the use of these methods to investigate subcellular localization and to identify any potential metabolites.

Recently, a new generation of peptide modified gemini surfactants was introduced demonstrating a superior in vitro transfection efficiency compared to the traditional unsubstituted gemini surfactants (Figure 1B) [30]. Herein, we aim to evaluate the CID-MS/MS fragmentation behaviour of eleven novel peptide modified gemini surfactants. The peptides are attached to the spacer region via an amide bond with variable hydrocarbon linkages that may affect the efficiency of the developed nano-formulations. The data from this study will be needed for 
developing multiple reaction monitoring (MRM) quantification MS/MS methods to probe the fate and the biodistribution of topically applied therapeutic gemini surfactant formulations.

\section{Material and methods Material}

Eleven novel peptide modified gemini surfactants were synthesized using previously reported synthetic methods [16]. Tested compounds were designated as $m-7 N(R)-m$ where $m$ is the alkyl tail carbon chain length, $\mathrm{m}=12$ or 16 and $\mathrm{R}$ is a chain of hydrocarbon linkers attached to amino acids: $\mathrm{R}=$ Glycyl-Hexyl-lysine, Glycyl-Hexyl-Trilysine, Glycyl-Undecyl-lysine, Glycyl-Undecyl-Trilysine, Hexyl-Trilysine and Undecyl-Trilysine. The general chemical structure of these gemini surfactants is shown in Figure 1B. Methanol (HPLC grade purity, Fisher Scientific, Nepean, ON, Canada), Water (HPLC grade purity, Fisher Scientific, Nepean, ON, Canada), and formic acid (purity 90\%, EMD Chemicals Inc., Merck KGaA, Darmstadt, Germany) were used as solvents.

\section{Sample preparation}

Stock solutions of $3 \mathrm{mM}$ gemini surfactants were prepared in methanol/water (50:50 v: v) containing $0.1 \%$ formic acid and stored at $-20 \circ \mathrm{C}$. Each sample was further diluted $1000 \mathrm{X}$ at the time of analysis using the same solvent.

\section{Mass spectrometric analysis}

Single stage MS analysis

Gemini surfactants were analyzed using an AB SCIEX QSTAR ${ }^{\circledR}$ XL quadrupole orthogonal time of-flight hybrid mass spectrometer (QqToF-MS) equipped with an electrospray ionization (ESI) source (AB SCIEX, Redwood City, CA, USA). The instrument was operated in the positive ion mode with declustering potential of $100 \mathrm{~V}$ and focusing potential of $290 \mathrm{~V}$. Sample aliquots were infused into the mass spectrometer at flow rate of $10 \mu \mathrm{L} / \mathrm{min}$ using an integrated Harvard syringe pump through a Turbo Ionspray Source, having a needle voltage of $5500 \mathrm{~V}$ and a temperature of $80^{\circ} \mathrm{C}$. Nitrogen was used as the drying gas and ESI nebulizing gas. A two-point external calibration was performed prior to the analysis of gemini surfactants using two singly charged calibration standards: cesium iodide (CsI, $\mathrm{m} / \mathrm{z}$ 132.9055, Sigma-Aldrich, Oakville, ON, Canada) and sex pheromone inhibitor iPD1 ( $\mathrm{m} / \mathrm{z}$ 829.5320, Bachem Bioscience Inc., PA, USA).

\section{Tandem mass spectrometric analysis}

Tandem mass spectrometric analysis of the tested gemini surfactants was performed using an AB SCIEX QTRAP ${ }^{\circledR} 4000$ hybrid triple quadrupole-linear ion trap mass spectrometer (QqLIT-MS) equipped with a "Turbo V Ion Spray” ESI source (AB SCIEX, Redwood City, CA, USA). Collision-induced dissociation (CID) was conducted using nitrogen as the collision gas. The instrument was operated in the positive ion mode with declustering potential in the range of 45-100 (optimized for each compound). Collision energy (CE) was also optimized for the range 20-40 eV to induce fragmentation while maintaining the abundance of the precursor ion. Samples were infused into the instrument at flow rate of $10 \mu \mathrm{L} / \mathrm{min}$ by using a model 11 Plus syringe pump (Harvard Apparatus, Holliston, MA, USA). Ionspray voltage was set at $5500 \mathrm{~V}$ with source temperature of $300^{\circ} \mathrm{C}$.

It is noteworthy that the MS/MS analysis of the all tested peptide-modified gemini surfactants was also conducted using the QSTAR ${ }^{\circledR}$. It generated similar MS/MS spectra to that produced by the QTRAP ${ }^{\circledR}$, confirming the elemental compositions of the projected product ions 
(Figure S1, Supplementary Material). However, MS/MS spectra acquired by the QTRAP® were more informative due to the ability of the linear ion trap to accumulate ions when performing the enhanced product ion scan.

\section{Multi-stage $M S^{3}$ analysis}

$\mathrm{MS}^{3}$ analysis of the selected second-generation ions was conducted on the AB SCIEX QTRAP ${ }^{\circledR} 4000$ instrument under the same optimized conditions mentioned above. Excitation energy (AF2) was set at the range of 20-100 to obtain abundant fragments of the selected second-generation ions.

\section{Results and discussion Single-stage MS analysis}

Full scan ESI-QqToF-MS analysis of all tested peptide-modified gemini surfactants showed an abundant triply charged $[\mathrm{M}+\mathrm{H}]^{3+}$ species (Table S1, Supplementary Material). In addition, some compounds with three terminal residues of amino acids showed a minor quadruply charged $[\mathrm{M}+2 \mathrm{H}]^{4+}$ species. The exact masses were assessed showing mass accuracies of less than 8 parts per million (ppm) mass error confirming the projected molecular structure of the tested gemini surfactants (Table S1, Supplementary Material). This mass accuracy was achieved by employing two-point external calibration prior to the analysis of the gemini surfactants. In fact, the accuracy of these measurements was similar to a recent work by our group which utilized internal calibration to assess mono-amino acid and di-amino acids substituted gemini surfactants [25].

Tandem mass spectrometric analysis

The fragmentation behavior of peptide modified gemini surfactants was evaluated using low-energy CID-MS/MS employing ESI-QqLIT-MS instrument. Structural variation within the tested gemini surfactants, namely the number of amino acid residues, the length of the hydrocarbon tails and the length of the incorporated hydrocarbon linker drove the MS/MS dissociation behavior. In addition, MS/MS experiments yielded compound-specific product ions which authenticate the molecular structure of their precursor ions. Such product ions could be utilized as diagnostic ions for the qualitative and quantitative analysis of the evaluated gemini surfactants.

The MS/MS fragmentation behavior of peptide modified gemini surfactants showed remarkable differences compared to traditional gemini surfactants [23, 24]. This is mainly due to the insertion of peptide segments within the gemini surfactant spacer region, resulting in the formation of peptide-related dissociation characteristics. The number of terminal amino acid residues in the spacer seems to play a major role in determining the MS/MS fragmentation pattern; hence, MS/MS analysis will be discussed based on the number of terminal amino acids residues. The following sections include detailed discussion of the fragmentation patterns of the 16-7N $\left(\mathrm{C}_{11}-\mathrm{K}_{3}\right)-16$ gemini surfactant as an illustrative example of compounds with the triterminal amino acids residues as it has the most complex MS/MS spectra among all tested compounds. In addition, the MS/MS dissociation behaviour of $16-7 \mathrm{~N}\left(\mathrm{G}-\mathrm{C}_{11}-\mathrm{K}\right)-16$ is briefly discussed to highlight the fragmentation of gemini surfactants with a mono-terminal amino acid moiety. The major product ions for peptide modified gemini surfactants with tri-terminal amino acids residues and mono-terminal amino acid moiety are displayed in Tables 2 and 3 respectively.

MS/MS fragmentation pathway of the peptide modified gemini surfactants with tri-terminal lysine moieties 
The fragmentation of the triply charged precursor ion of 16-7N(C11-K3)-16 gemini surfactant resulted in the formation of three initial diagnostic product ions that have their unique subsequent dissociation pathways (Figure 2, Table 1). Two initial product ions arise from the loss of one of the terminal lysine moieties producing either a doubly charged product ion (A) observed at $\mathrm{m} / \mathrm{z} 538.54$ or a triply charged product ion (B) observed at $\mathrm{m} / \mathrm{z} 359.36$. The third initial product ion results from the loss of a $\mathrm{NH}_{3}$ moiety generating a triply charged product ion (C) observed at $\mathrm{m} / \mathrm{z}$ 396.38. The coexistence of the three initial product ions suggests a competition between different fragmentation mechanisms. While both ions (A) and (B) are formed by losing one of the terminal lysine residues from the precursor ion, they have different charge status implying the presence of different fragmentation mechanism for cleaving the amide bond.

As indicated earlier, the presence of peptides within the gemini surfactants offered the compound protonated peptide characteristics, unlike conventional gemini surfactants [23, 24]. The dissociation of protonated peptides can be explained by the 'mobile proton' model: a comprehensive model that suggests a competition between charge-remote and charge-directed reactions to predict the fragmentation process [31-33]. Under low-energy conditions such as CID, charge-directed reactions are believed to be the major pathway for peptide dissociation in which bond cleavage is initiated by active involvement of the ionizing proton [34]. Thus, the location of the ionizing proton on the peptide chain could determine the fragmentation mechanism [33]. As such, the composition of the amino acids (the presence or absence of a basic residue), the sequence, size and charge state of the investigated peptide will play a crucial role in determining the MS/MS fragmentation pattern.

The gemini surfactant 16-7N(C11-K3)-16 has a chain of three branched lysine moieties. Lysine is a basic amino acid that is most probably protonated at the $\varepsilon$-amino group of the side chain. Amid bond cleavage is initiated by nucleophilic attack by the lysine side chain on the amide bond [35, 36]. The first step of the reaction involves mobilization of the proton of the lysine side chain to the nitrogen of the C-terminal neighboring amide bond (Figure 3). Subsequently, nucleophilic attack by the lysine side chain on the carbon of the protonated amide bond leading to the cleavage of the amide bond and the formation of a protonated $\alpha$-amino- $\varepsilon$ caprolactam ion observed at $\mathrm{m} / \mathrm{z} 129.10\left(\mathrm{~b}_{1}\right)$ (Figure 3). A complementary ion at $\mathrm{m} / \mathrm{z} 538.5$ (product ion A) is formed rather than a neutral species as in the case of peptides due to the presence of quaternary amines that exist within the structure of gemini surfactants (Figure 1B, Figure 3).

In fact, the formation of the product ion at $\mathrm{m} / \mathrm{z} 129.10$ is a characteristic of lysine containing peptides [35-37]. The loss of lysine through this mechanism explains the formation of product ion (A) the doubly charge compound, however, it does not explain the formation of product ion (B), the triply charged species of the same structure (Figure 2), suggesting the presence of alternative MS/MS dissociation mechanism.

Two mechanisms can be proposed for the formation of the product ion (B) observed at $\mathrm{m} / \mathrm{z}$ 359.36. The first could be explained by the established fragmentation mechanism termed $\left(\mathrm{a}_{\mathrm{x}}\right.$ $-\mathrm{y}_{\mathrm{x}}$ ) which leads to integrated formation of $\mathrm{a}_{\mathrm{x}}$ and $\mathrm{y}_{\mathrm{x}}$ ions [38, 39]. This dissociation is focused on the cleavage of the amide bond and $\mathrm{C} \alpha-\mathrm{C}$ amide bond resulting in the formation of protonated imine, carbon monoxide and product ion B (i.e. protonated C-terminal fragment) (Figure 4) [38]. Following the expulsion of the weakly bound carbon monoxide, a proton-bound dimer between the $\mathrm{N}$ terminal and the C-terminal fragments is formed. Under low-energy CID conditions, the formed dimer has a long lifetime allowing for numerous proton transfers among product ions to occur. As a result, the dimer is dissociated to form either product ion B (i.e. the $\mathrm{y}_{2}$ ion based on Roepstorff nomenclature for peptide fragmentation[40]) or ion $\mathrm{a}_{1}$ which is observed at $\mathrm{m} / \mathrm{z}$ 101.10 (Figure 4). It should be noted that ions $\mathrm{B}$ and $\mathrm{a}_{1}$ were only observed in gemini surfactants 
with longer hydrophobic linker chain $\left(C_{11}\right)$ and not in shorter linker $\left(C_{6}\right)$ (Table 1$)$. This is in agreement with previously reported behavior of mono and di- amino acid substituted gemini surfactants in which no ion B analogues was observed [25].

Alternative mechanism that could lead to the formation of product ion (B) is simply the same as that of product ion (A) (Figure 3), however; a proton transfer from the amide-nitrogen of the protonated $\alpha$-amino- $\varepsilon$-caprolactam to the $\varepsilon$-amino group of the remaining lysine (c-terminus) is required. Csonka et al. indicated the possibility of such a dissociation to occur especially when the c-terminal part of the compound has high enough proton affinity to compete with the $\alpha$ amino-e-caprolactam [36]. In the tested compound, the $\varepsilon$-amino group of the c- terminal has a higher $p k a$ value than the amide-nitrogen, thus it has higher proton affinity raising the possibility for the ion transfer to take place. As such, it is possible that two mechanisms are simultaneously involved in the formation of product ion (B).

In addition to product ions $\mathrm{A}$ and $\mathrm{B}$, Product ion (C) at $\mathrm{m} / \mathrm{z} 396.38$ results from the neutral loss of a $\left(\mathrm{NH}_{3}\right)$ moiety (Figure S2, Supplementary Material; Figure 2). This is expected as protonated peptides under low-energy CID conditions often undergo neutral losses of small molecules such as water or ammonia [34]. The loss of ammonia has been reported mainly in basic amino acid residues such as lysine, arginine, asparagine and glutamine [34]. A chargedirected fragmentation mechanism has been proposed for the elimination of ammonia from the lysine side chain [35]. As such, protonation of the side chain is required. Since $\varepsilon$-amino group is the most favored protonation site in lysine, mobilization of protons is not needed. Dookeran et al. demonstrated utilizing an $\alpha-{ }^{15} \mathrm{~N}$ protonated lysine that the loss of the $\mathrm{NH}_{3}$ moiety involves in particular the nitrogen of the side chain [37]. When lysine is located at the peptide N-terminus, like in the tested gemini surfactants, the loss of ammonia occurs via nucleophilic attack by the $\mathrm{N}$ terminal amino group resulting in the formation of pipecolic acid (Figure S2, Supplementary Material) [36]. It is noteworthy that the proposed fragmentation pathways forming the three initial product ions could involve either one of the two $\mathrm{N}$-terminal lysine moieties, leading to identical product ions. In fact, the various observed ions could be a mixture of two species losing either lysine moiety terminal. Both losses will not affect the produced product ions that can still efficiently be used for both qualitative and quantitative applications.

Dissociation of product ion A

The dissociation of product ion (A) starts with the loss of the quaternary ammonium headgroup and the attached aliphatic tail resulting in the formation of two complementary ions: product ion (1) at $\mathrm{m} / \mathrm{z} 270.31$ a singly charged ion and a minor singly charged product ion (2) observed at $\mathrm{m} / \mathrm{z} 806.76$ (Figure 5, Table 1). In addition, a doubly charged species was observed at $m / z 403.88$ (2) which shares the same molecular structure of product ion (2) albeit doubly charged. This suggests the existence of an alternative ion formation mechanism. It could be explained by a homolytic cleavage of the $\mathrm{N}-\mathrm{C}$ bond between the quaternary ammonium headgroup and the hydrocarbon tail resulting in the neutral loss of the aliphatic tail (hexadec-1ene) and the formation of a doubly charged minor product ion at $\mathrm{m} / \mathrm{z} 426.41\left(2^{*}\right.$ ) (Figure 5). In agreement with the previously observed behavior of mono and di- amino acid substituted gemini surfactants [25], the close proximity of the two positively charged head groups of ions such as $\left(2^{*}\right)$ could make the ion relatively unstable which easily fragments by the subsequent loss of a head group as dimethylamine leading to the formation of (2`) ion at $m / z 403$.88. Such a behavior was consistent among all the evaluated gemini surfactants. In fact, in some cases the intermediate ion (i.e. $2^{*}$ ) was abundant enough to enable for $\mathrm{MS}^{3}$ analysis that supported the projected molecular structure of this ion $\left(2^{*}\right)$ (Table S2, Supplementary Material). The formation of such unstable intermediate ions and their subsequent stable product ions (i.e. ion 2 in this case) was commonly noticeable in the various tested gemini surfactants. It will be referenced frequently in the text as an intermediate ion. 
Product ion (2`) subsequently yields the formation of four product ions (Figure 5). The first involves the loss of the headgroup and the attached aliphatic tail (ion 1 ) at $\mathrm{m} / \mathrm{z} 270.31$ producing a singly charged product ion (3) at $\mathrm{m} / \mathrm{z} 537.44$. A second ion is formed via the neutral loss of the aliphatic chain and the formation of intermediate doubly charged ion, as discussed above, at $\mathrm{m} / \mathrm{z} 291.75$ (ion structure is not shown) which easily loses the dimethylamine head group generating a doubly charged species (3`) at $\mathrm{m} / \mathrm{z}$ 269.23. The third and fourth ions are formed as a result of eliminating the terminal lysine moiety leading to the formation of a singly charged ion (4) at $\mathrm{m} / \mathrm{z} 678.66$ and the corresponding doubly charged ion (4) at $\mathrm{m} / \mathrm{z} 339.83$ (dotted arrows originating from ion 403.8). As shown in Figure 3, this cleavage is usually initiated by nucleophilic attack of the lysine side chain on the amide bond releasing $\mathrm{m} / \mathrm{z} 129.10$ ion $\left(b_{2}\right)$ as a protonated $\alpha$-amino- $\varepsilon$-caprolactam and forming product ion (4). Ion (4) on the other hand could either result from the same mechanism as ion (4) but it requires a proton transfer from the protonated $\alpha$-amino- $\varepsilon$-caprolactam to the complementary c-terminal ion or through the $\left(a_{x}-y_{x}\right)$ peptide fragmentation mechanism (Figure 4). Unlike product ion (2), fragmentation of the singly charged ion (2) produces only two product ions: ions (3) and (4) (Figure 5).

Ion (3`) at $\mathrm{m} / \mathrm{z} 269.23$ undergoes neutral loss of ammonia forming pipecolic acid derivative compound at $\mathrm{m} / \mathrm{z} 260.71$ (5`) (Figure 5). Furthermore, (3`) loses another terminal lysine moiety forming a single-charged ion (6) at $\mathrm{m} / \mathrm{z} 409.35$ and a double-charged ion (6`) at $\mathrm{m} / \mathrm{z}$ 205.18. Similar to ion (3)), ion (3) also eliminates an ammonia group producing ion (5) at $\mathrm{m} / \mathrm{z} 520.42$ and loses a lysine moiety to produce ion (6). Ion (6) can also be formed via the loss of alkyl tail from ion (4) as well as ion (4); the latter can additionally yield ion (6`) as shown in Figure 5. Finally, ions (5) and (5`) can also yield the formation of product ion (6) through the loss of the pipecolic acid ring (Figure 5). It can be speculated that this loss occurred by the mobilization of the proton from the pipecolic acid ring to the nitrogen of the amide bond followed by nucleophilic attack either by the carbonyl group releasing pipecolic acid which was observed at $\mathrm{m} / \mathrm{z} 112.07$ or by the pipecolic acid ring's amine resulting in opening the ring and forming caprolactam ion which was also observed at m/z 114.09 (Figure 5).

Product ion (6`) experiences loss of ammonia group forming ion (7) at $\mathrm{m} / \mathrm{z} 196.67$ and eliminates the last lysine moiety forming ion (8) at $\mathrm{m} / \mathrm{z}$ 281.26. It should be noted that ion (8) at $\mathrm{m} / \mathrm{z} 281.26$ was also produced by ion (6); however, $\mathrm{MS}^{3}$ analysis did not show any second generation product ions at $\mathrm{m} / \mathrm{z}$ 129.10, which corresponds to the elimination of lysine as a protonated $\alpha$-amino- $\varepsilon$-caprolactam (Table S2, Supplementary Material). This finding supports the theory of the proton transfer from the protonated $\alpha$-amino- $\varepsilon$-caprolactam to the c-terminal fragment ion that we proposed earlier as a possible mechanism to justify the formation of product ion B.

\section{Dissociation of product ion $B$}

Product ion (B) dissociates via two fragmentation pathways; firstly by the loss of an $\mathrm{NH}_{3}$ moiety from the terminal lysine producing pipecolic acid derivative, product ion (9) at $\mathrm{m} / \mathrm{z}$ 353.68 (Figure 6, Table 1). The second product ion results from the loss of the terminal lysine amino acid residue (observed at $\mathrm{m} / \mathrm{z} 129.10$ [b2]) by amide bond cleavage forming a doubly charged product ion (10) at $\mathrm{m} / \mathrm{z}$ 474.49. Elimination of the pipecolic acid part of ion (9) also leads to the formation of ion (10) which subsequently dissociates by eliminating the last terminal lysine, forming ion (11) observed at $\mathrm{m} / \mathrm{z}$ 410.44. Furthermore, ion (10) loses the tail region and the attached head forming the previously mentioned singly and doubly charged ions designated as (4) and (4). As it can be seen, the complexity of the MS/MS spectra supports the notion that some ions may be formed from various product ions as in the case of the product ions (4) and (4). Such observation is supported by second generation $\mathrm{MS}^{3}$ analysis (Table S2, Supporting Material). Both of these ions further dissociate as shown in Figure 6. Ion (11) also loses the 
aliphatic tail and the attached head group yielding ion (12) and (12') at $\mathrm{m} / \mathrm{z} 550.57$ and $\mathrm{m} / \mathrm{z}$ 275.79 respectively supported by second generation $\mathrm{MS}^{3}$ analysis (Table S2, Supplementary Material). Both ions subsequently eliminate the remaining dimethylalkenammonium ion forming the product ion (8) at $\mathrm{m} / \mathrm{z} 281.26$ (Figure 6).

Dissociation of product ion $C$

Product ion (C) was the source of six product ions (Figure 7) which is much more complex than product ions $\mathrm{A}$ or $\mathrm{B}$. This is expected since product ion $\mathrm{C}$ retains the same structural backbone of the precursor ion with the simple loss of $\mathrm{NH}_{3}$ moiety. The first two product ions arise from the loss of pipecolic acid re-forming product ions (A) or (B) which was confirmed by $\mathrm{MS}^{3}$ analysis (Table S2, Figure S3, Supplementary Material). On the other hand, cleavage of the peptide bond of the lysine with intact side chain resulted in the formation of ions 9 and 9 observed at $\mathrm{m} / \mathrm{z} 353.68$ and $\mathrm{m} / \mathrm{z} 530.02$ (Figure 7, Table 1) respectively which differs only in the charge state due to variations in the formation mechanisms as disused earlier in details in the section entitled "Dissociation of product ion A". Interestingly, $\mathrm{MS}^{3}$ analysis of ion (C) revealed that product ions (A) and (B) were of lower abundance than product ions 9 and 9' (Figure S3, Supplementary Material). This could be attributed to the ease of the cleavage of the amide bond linked to the lysine side chain $\varepsilon$-amino group in comparison to the loss of pipecolic acid.

Product ion (C) can also eliminates another ammonia group from the second terminal lysine producing a triply charge ion (13) observed at $\mathrm{m} / \mathrm{z}$ at 390.70 (Figure 7 , Table 1 ). Since the elimination of the ammonia is charge-directed, mobilization of the proton from the pipecolic acid ring to the lysine $\varepsilon$-amino group is required. Ion (13) subsequently loses one of the pipecolic acids yielding the previously mentioned ions (9) and (9`) which was confirmed by second generation $\mathrm{MS}^{3}$ analysis (Table S2). Finally, product ion $\mathrm{C}$ undergoes a neutral loss of the aliphatic tail forming an unstable intermediate at $\mathrm{m} / \mathrm{z} 321.63$ (not shown) which easily loses dimethylamine group forming a triply charged ion (14) at $\mathrm{m} / \mathrm{z}$ 306.61. Similar to past observation, such an intermediate ion was occasionally observed and its genesis was confirmed by $\mathrm{MS}^{3}$ analysis.

Ion (14) eliminates the remaining ammonium headgroup and the associated aliphatic tail producing the product ion (15) at $\mathrm{m} / \mathrm{z}$ 324.76. It also undergoes neutral loss of the tail through hemolytic cleavage of the N-C bond forming, as above, unstable intermediate at $m / z 231.86$ that subsequently losses the head group yielding ion (15`) at $\mathrm{m} / \mathrm{z} 216.84$. Ion (16) observed at $\mathrm{m} / \mathrm{z}$ 300.94 is also produced from ion (13) after losing the dimethylalkenammonium ion and from ion (14) after the neutral loss of ammonia which was confirmed by $\mathrm{MS}^{3}$ analysis (Figure 7, Table S2). Ion (16) follows same pathway as ion 14 forming ion (17) at $\mathrm{m} / \mathrm{z} 316.25$ and ion (17`) at $\mathrm{m} / \mathrm{z}$ 211.17. Both ion 17 and $17^{`}$ was generated by loss of ammonia from ions 15 and $15^{`}$. Ions 15 , 15`, 17 and $17^{`}$ further cleaved various amid bonds producing smaller structures product ions as illustrated in Figure 7.

Ions 9 and 9 follow similar fragmentation pattern as ion (13), firstly by losing one of the dimethylalkenammonium ions then by eliminating the second one (Figure 7, Table 1).The produced product ions later fragmented to smaller ions in a similar fashion by cleaving the amide bond and/or ejecting lysine moieties as illustrated in Figure 7.

In order to support the proposed fragmentation pathways of the peptide-modified gemini surfactants with tri-terminal lysine moieties, isotopically labeled analogues were evaluated. This include compounds $16-7 \mathrm{~N}\left(\mathrm{G}-\mathrm{C}_{11}-\mathrm{K}_{\mathrm{D}}-\mathrm{K}_{2}\right)-16$ and $16-7 \mathrm{~N}\left(\mathrm{G}-\mathrm{C}_{6}-\mathrm{K}_{\mathrm{D}}-\mathrm{K}_{2}\right)-16$ where $\mathrm{K}_{\mathrm{D}}$ is a deuterated lysine moiety bearing four deuterium atoms. The MS/MS analysis revealed an increased $\mathrm{m} / \mathrm{z}$ values in the product ions containing the deuterated lysine such as product ions (A), (B) and (C) (Figure S4, Supplementary Material). Moreover, fragment ions (8), (11), (12) 
and (12) that bear no deuterated region showed identical $\mathrm{m} / \mathrm{z}$ values, confirming the proposed fragmentation pathway (Figure S4, Supplementary Material).

MS/MS fragmentation pathway of the peptide modified gemini surfactants with mono-terminal lysine moiety

Gemini surfactant $16-7 \mathrm{~N}\left(\mathrm{G}-\mathrm{C}_{11}-\mathrm{K}\right)-16$ is used as an illustrative example of peptide modified gemini surfactants functionalized with single terminal lysine moiety (Figure 8). Similar to the fragmentation pathway of $16-7 \mathrm{~N}\left(\mathrm{C}_{11}-\mathrm{K}_{3}\right)-16$ gemini surfactant, dissociation of $16-7 \mathrm{~N}(\mathrm{G}-$ $\left.\mathrm{C}_{11}-\mathrm{K}\right)-16$ compound started with either the elimination of the lysine moiety and/or the neutral loss of amino group. Elimination of the lysine residue through the cleavage of the amide bond produced ion (A), a doubly charged product ion observed at $\mathrm{m} / \mathrm{z} 438.95$, and released its complimentary ion $\left(\mathrm{b}_{1}\right)$ at $\mathrm{m} / \mathrm{z} 129.10$ as a protonated $\alpha$-amino- $\varepsilon$-caprolactam (Figure 8 , Table 2 ). Unlike 16-7N $\left(\mathrm{C}_{11}-\mathrm{K}_{3}\right)-16$ gemini surfactants, the formation of a triply charged product ion after the elimination of the lysine residues from $16-7 \mathrm{~N}\left(\mathrm{G}-\mathrm{C}_{11}-\mathrm{K}\right)-16$ was not observed. This is possibly due to the higher proton affinity of the $\alpha$-amino- $\varepsilon$-caprolactam compared to the cterminal product ions. A charge-directed loss of the lysine $\varepsilon$-amino group from the precursor ion resulted in the formation of pipecolic acid derivative product ion (B) at $\mathrm{m} / \mathrm{z} 329.99$ which can subsequently eradicate the pipecolic acid ring forming ion (A) (Figure 8).

As indicated earlier, product ion (A) undergoes the loss of the dimethylalkenammonium ion (1) generating both a single-charged product ion (2) at $m / z 607.59$ and a double-charged product ion (2`) at $\mathrm{m} / \mathrm{z} 304.30$ (Figure 8 , Table 2). Both product ions experience a loss of the last dimethylalkenammonium ion producing product ion (3) at $\mathrm{m} / \mathrm{z}$ 338.28. In addition, ion (2`) produced ion (3`), the doubly charged analog of ion (3).

Ion (B) also loses ion (1) producing ion (4) at $\mathrm{m} / \mathrm{z} 240.22$ which either eliminates the last dimethylalkenammonium ion generating ion (5) at $\mathrm{m} / \mathrm{z} 225.18$ and/or removes the pipecolic acid ring resulting in the formation of ion (2`) (Figure 8, Table 2). Further dissociations of ion (5) are self-explanatory resulting in the production of ion (3) and (3)). Similar to other compounds, the genesis and structures of all ions observed in Figure 8 were confirmed by $\mathrm{MS}^{3}$ analysis (data not shown).

Universal MS/MS fragmentation pattern of the novel peptide modified gemini surfactants Similarities in the fragmentation behaviour of the peptide modified gemini surfactants resulted in the establishment of a universal MS/MS fragmentation pattern (Figure 9) that can be applied to any related structure. The universal fragmentation pathway begins with both the cleavage of the peptide bond forming a doubly charged product ion (A) and the neutral loss of the lysine's $\varepsilon^{-}$ amino group producing pipecolic acid derivative product ion (B).

Two dissociation pathways are proposed for product ion (A). First, a loss of one quaternary ammonium headgroup and the attached aliphatic tail producing two complimentary ions: dimethylalkenammonium product ion (1) and the singly charged product ion (2). The second pathway occurs via homolytic cleavage of the $\mathrm{N}-\mathrm{C}$ bond between the quaternary ammonium headgroup and the hydrocarbon tail resulting in the neutral loss of the aliphatic tail and the production of a doubly charged intermediate ion that easily eradicates the dimethylamine head group, probably due to the close proximity of the two positively charged head groups, generating product ion (2). In some cases the intermediate ion was abundant enough to conduct $\mathrm{MS}^{3}$ analysis to support proposition. Both ions (2) and (2`) also undergo subsequent loss of dimethylalkenammonium ion forming ions (3) and (3`) (Figure 9).

On the other hand, ion (B) dissociates by the loss of dimethylalkenammonium ion forming a triply charged ion (4) which subsequently eliminates another dimethylalken ammonium ion to produce ion (5). Product ions (B), (4) and (5) produced ions (A), (2`) and (3`) respectively through the removal of the pipecolic acid ring as illustrated in Figure 9. 


\section{Conclusion}

In this work, we utilized ESI-QqToF-MS and ESI-QqLIT-MS to study the CID-MS/MS fragmentation behaviour of eleven novel peptide-modified gemini surfactants. Exact mass measurements confirmed the projected molecular composition of the evaluated compounds showing mass accuracies of less than $8 \mathrm{ppm}$. In addition, tandem mass spectrometric analysis generated compound-specific product ions authenticating the chemical structure of their precursor ions. The genesis of these product ions was further confirmed by $\mathrm{MS}^{3}$ analysis (Table S2, Supplementary Material), allowing for the development of fragmentation pattern that could be used as a fingerprint for accurate identification of the tested compounds.

In general, the MS/MS dissociation was centered on the attached amino acids in which peptide bonds were cleaved for the generation of diagnostic product ions. Furthermore, neutral loss of an ammonia group from the amino acid side chain was dominant within the evaluated structures. Elimination of one or both of the quaternary ammonium headgroups and the attached aliphatic tail was also observed. It should be noted that the number of terminal amino acid residues in the spacer and the length of the inserted hydrocarbon linker affected the dissociation behaviour. For example, the formation of the triply charged initial product ions after eliminating a terminal lysine residue was only observed in gemini surfactants with longer hydrophobic linker chain $\left(\mathrm{C}_{11}\right)$ and with tri-terminal amino acids residues. Nevertheless, similarities in the fragmentation behaviour among all the tested gemini surfactants resulted in the production of a universal fragmentation pattern as illustrated in Figure 9. This universal fragmentation pattern can be utilized to predict the dissociation behaviour of new compounds with similar general structural features. In addition, it will be utilized for the development of qualitative and quantitative MS-based methods to probe the fate and biodistribution of topically applied therapeutic gemini surfactant formulations. We are currently quantitatively evaluating the distribution of lead gemini surfactants within skin tissues for therapeutic applications. This data will be reported upon completion.

\section{Acknowledgements}

Mays Al-Dulaymi is a fellow of the Canadian Institutes of Health Research Training grant in Health Research Using Synchrotron Techniques (CIHR-THRUST) and thanks the program for financial support. The authors acknowledge Mr. Ken Thoms for his technical assistant on using the QSTAR system. Also, we thank Ms. Deborah Michel and Mr. Waleed Mohammed-Saeid for providing Ms. Al-Dulaymi training on the MS instrumentation. The research is funded by the Natural Sciences and Engineering Research Council of Canada (NSERC) Discovery grant. The QTRAP 4000 instrument was obtained via Canada Foundation for Innovation (CFI) grant. 
(A)

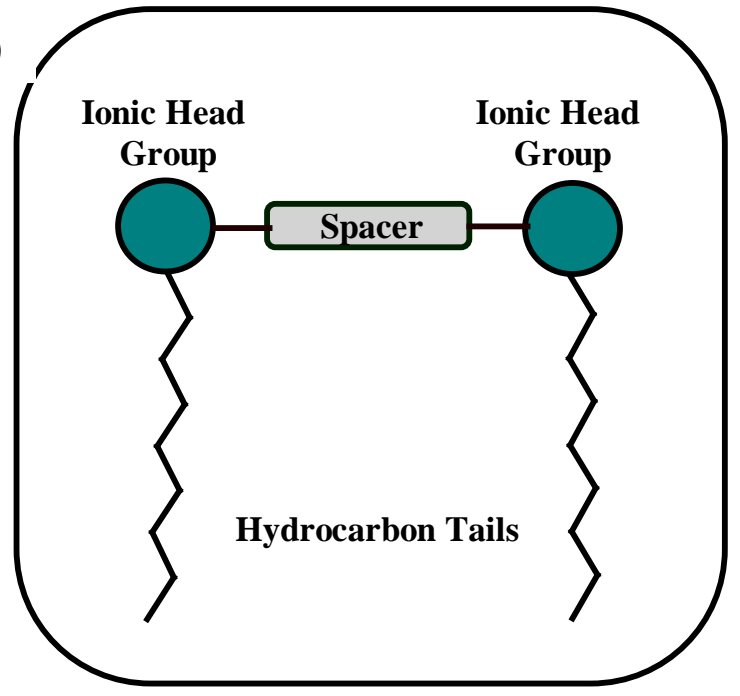

(B)

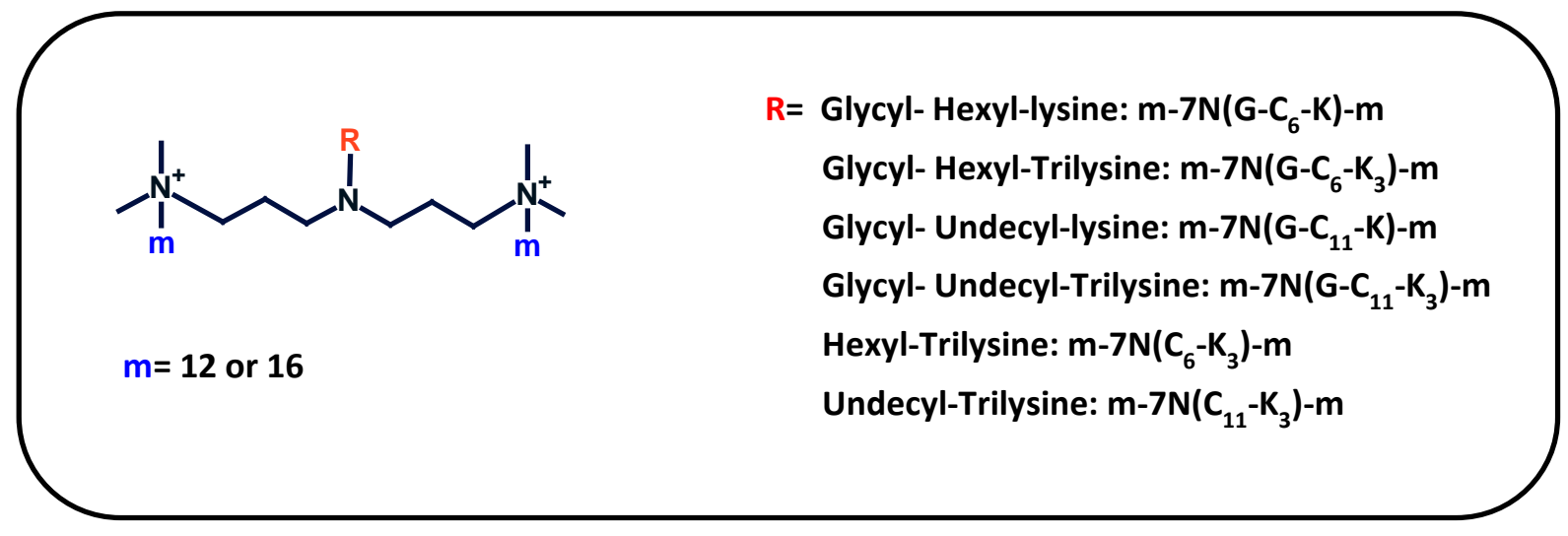

Figure 1. (A) Prototype of gemini surfactants showing the two ionic head groups, hydrocarbon tails and the spacer and (B) schematic representation of the general structure of the tested peptide modified gemini surfactants. 
Table 1. Precursor ions and product ions observed during MS/MS analysis of $[\mathrm{M}+\mathrm{H}]^{3+}$ ions of the peptide modified gemini surfactants with tri-terminal lysine moieties.

\begin{tabular}{|c|c|c|c|c|c|c|c|c|c|}
\hline & Gemini surfactants & $\begin{array}{l}12-7 N\left(G-C_{11^{-}}\right. \\
\left.K_{3}\right)-12\end{array}$ & $\begin{array}{l}16-7 N\left(G-C_{11^{-}}\right. \\
\left.K_{3}\right)-16\end{array}$ & $\begin{array}{l}12-7 N\left(G-C_{6^{-}}\right. \\
\left.K_{3}\right)-12\end{array}$ & $\begin{array}{l}16-7 N\left(G-C_{6^{-}}\right. \\
\left.K_{3}\right)-16\end{array}$ & $\begin{array}{l}12-7 N\left(C_{11^{-}}\right. \\
\left.K_{3}\right)-12\end{array}$ & $\begin{array}{l}16-7 N\left(C_{11^{-}}\right. \\
\left.K_{3}\right)-16\end{array}$ & $\begin{array}{l}12-7 N\left(C_{6^{-}}\right. \\
\left.K_{3}\right)-12\end{array}$ & $\begin{array}{l}16-7 N\left(C_{6}-\right. \\
\left.K_{3}\right)-16\end{array}$ \\
\hline & & $m / z$ & $m / z$ & $m / z$ & $m / \mathbf{z}$ & $m / \mathbf{z}$ & $m / z$ & $m / \mathbf{z}$ & $m / \mathbf{z}$ \\
\hline & Precursor ions & 383.6895 & 421.0633 & 360.3344 & 397.7076 & 364.6828 & 402.0593 & 341.3257 & 378.7015 \\
\hline Ion \# & Product ions & $m / z$ & $m / z$ & $m / z$ & $m / z$ & $m / z$ & $m / z$ & $m / z$ & $m / z$ \\
\hline A & {$\left[\mathrm{M}-\mathrm{C}_{6} \mathrm{H}_{13} \mathrm{~N}_{2} \mathrm{O}\right]^{2+}$} & 510.98 & 567.04 & 475.94 & 532.37 & 482.47 & 538.54 & 447.43 & 503.50 \\
\hline $\mathbf{B}\left(\mathbf{y}_{2}\right)$ & {$\left[\mathrm{M}-\mathrm{C}_{6} \mathrm{H}_{12} \mathrm{~N}_{2} \mathrm{O}\right]^{3+}$} & 340.99 & 378.37 & & & 321.98 & 359.36 & & \\
\hline C & {$\left[\mathbf{M}-\mathrm{NH}_{3}\right]^{3+}$} & 378.01 & 415.39 & 354.65 & 392.03 & 359.01 & 396.38 & 335.65 & 373.02 \\
\hline $\mathbf{b}_{\mathbf{x}}$ & $\mathrm{C}_{6} \mathrm{H}_{13} \mathrm{~N}_{2} \mathrm{O}$ & 129.10 & 129.10 & 129.10 & 129.10 & 129.10 & 129.10 & 129.10 & 129.10 \\
\hline $\mathbf{a}_{1}$ & $\mathrm{C}_{5} \mathrm{H}_{13} \mathrm{~N}_{2}$ & 101.10 & 101.10 & & & 101.10 & 101.10 & & \\
\hline 1 & Dimethylalkenammonium & 214.25 & 270.31 & 214.25 & 270.31 & 214.25 & 270.31 & 214.25 & 270.31 \\
\hline 2 & {$\left[M-\left(b_{x}\right)-\operatorname{ion}(1)\right]^{+}$} & 807.71 & 863.78 & 737.63 & 793.70 & 750.69 & 806.76 & 680.62 & 736.68 \\
\hline 2 & {$\left[M-\left(b_{x}\right)-\operatorname{ion}(1)\right]^{2+}$} & 404.36 & 432.39 & 369.32 & 397.35 & 375.85 & 403.88 & 340.81 & 736.68 \\
\hline 3 & {$\left[M-\left(b_{x}\right)-2 \operatorname{ion}(1)\right]^{+}$} & 594.47 & 594.47 & 524.40 & 524.40 & 537.44 & 537.44 & 467.37 & 467.37 \\
\hline 3 & {$\left[M-\left(b_{x}\right)-2 \operatorname{ion}(1)\right]^{2+}$} & 297.74 & 297.74 & 262.70 & 262.70 & 269.23 & 269.23 & 234.19 & 234.19 \\
\hline 4 & {$\left[M-2\left(b_{x}\right)-\operatorname{ion}(1)\right]^{+}$} & 679.62 & 735.68 & 609.54 & 665.59 & 622.60 & 678.66 & 552.52 & 608.58 \\
\hline 4 & {$\left[M-2\left(b_{x}\right)-\operatorname{ion}(1)\right]^{2+}$} & 340.31 & 368.19 & 305.27 & 333.30 & 311.80 & 339.83 & 276.76 & 304.80 \\
\hline 5 & {$\left[M-\left(b_{x}\right)-\left(N_{3}\right)-2 \operatorname{ion}(1)\right]^{+}$} & 577.44 & 577.44 & 507.36 & 507.36 & 520.42 & 520.42 & 450.34 & 450.34 \\
\hline 5 & {$\left[M-\left(b_{x}\right)-\left(N_{3}\right)-2 \operatorname{ion}(1)\right]^{2+}$} & 289.22 & 289.22 & 254.18 & 254.18 & 260.71 & 260.71 & 225.67 & 225.67 \\
\hline 6 & {$\left[M-2\left(b_{x}\right)-2\right.$ ion(1)] ${ }^{+}$} & 466.94 & 466.94 & 396.30 & 396.30 & 409.35 & 409.35 & 339.27 & 339.27 \\
\hline 6 & {$\left[M-2\left(b_{x}\right)-2 \operatorname{ion}(1)\right]^{2+}$} & 233.69 & 233.69 & & & 205.18 & 205.18 & & \\
\hline
\end{tabular}




\begin{tabular}{|c|c|c|c|c|c|c|c|c|c|}
\hline 7 & {$\left[\mathrm{M}-2\left(\mathrm{~b}_{\mathrm{x}}\right)-\left(\mathrm{NH}_{3}\right)-2 \mathrm{ion}(1)\right]^{2+}$} & 225.18 & 225.18 & 190.14 & 190.14 & 196.67 & 196.67 & 161.63 & 161.63 \\
\hline 8 & {$\left[M-3\left(b_{x}\right)-2 \operatorname{ion}(1)\right]^{+}$} & 338.27 & 338.27 & 268.19 & 268.19 & 281.26 & 281.26 & 211.18 & 211.18 \\
\hline 9 & {$\left[\mathrm{M}-\left(\mathrm{b}_{\mathrm{x}}\right)-(\mathrm{NH} 3)\right]^{3+}$} & 335.31 & 372.69 & 311.96 & 349.33 & 316.31 & 353.68 & 292.95 & 330.32 \\
\hline 9` & {$\left[\mathrm{M}-\left(\mathrm{b}_{\mathrm{x}}\right)-(\mathrm{NH} 3)\right]^{2+}$} & 502.47 & 558.53 & 467.43 & 523.49 & 473.96 & 530.02 & 438.92 & 494.98 \\
\hline 10 & {$\left[M-2\left(b_{x}\right)\right]^{2+}$} & 446.94 & 503.00 & 411.90 & 467.96 & 418.43 & 474.49 & 383.39 & 439.45 \\
\hline 11 & {$\left[\mathbf{M}-3\left(\mathbf{b}_{\mathbf{x}}\right)\right]^{2+}$} & 382.89 & 438.95 & 347.85 & 403.91 & 354.38 & 410.44 & 319.34 & 375.40 \\
\hline 12 & {$\left[M-3\left(b_{x}\right)-\operatorname{ion}(1)\right]^{+}$} & 551.52 & 607.59 & 481.44 & 537.51 & 494.50 & 550.57 & 424.43 & 480.49 \\
\hline 12 & {$\left[M-3\left(b_{x}\right)-\operatorname{ion}(1)\right]^{2+}$} & 276.27 & 304.30 & 241.23 & 269.26 & 247.75 & 275.79 & 212.71 & 240.75 \\
\hline 13 & {$\left[\mathrm{M}-2\left(\mathrm{NH}_{3}\right)\right]^{3+}$} & 372.34 & 409.71 & 348.97 & 386.62 & 353.33 & 390.70 & 329.97 & 367.35 \\
\hline 14 & {$\left[\mathrm{M}-\left(\mathrm{NH}_{3}\right)-\text { ion(1) }\right]^{3+}$} & 306.93 & 325.62 & 283.57 & 302.26 & 287.92 & 306.61 & 264.57 & 283.25 \\
\hline 15 & {$\left[\mathrm{M}-\left(\mathrm{NH}_{3}\right)-2 \text { ion }(1)\right]^{2+}$} & 353.27 & 353.27 & 318.23 & 318.23 & 324.76 & 324.76 & 289.72 & 289.723 \\
\hline $15^{`}$ & {$\left[\mathrm{M}-\left(\mathrm{NH}_{3}\right)-2 \text { ion }(1)\right]^{3+}$} & 235.85 & 235.85 & 212.49 & 212.49 & 216.84 & 216.84 & 193.48 & 193.48 \\
\hline 16 & {$\left[\mathrm{M}-2\left(\mathrm{NH}_{3}\right)-\operatorname{ion}(\mathbf{1})\right]^{3+}$} & 301.26 & 319.94 & 277.90 & 296.58 & 282.25 & 300.94 & 258.89 & 277.58 \\
\hline 17 & {$\left[\mathrm{M}-2\left(\mathrm{NH}_{3}\right)-2 \text { ion(1)] }\right]^{2+}$} & 344.76 & 344.76 & 309.72 & 309.72 & 316.25 & 316.25 & 281.21 & 281.21 \\
\hline $17^{\circ}$ & {$\left[\mathrm{M}-2\left(\mathrm{NH}_{3}\right)-2\right.$ ion(1)] ${ }^{3+}$} & 230.17 & 230.17 & 206.82 & 206.82 & 211.17 & 211.17 & 187.81 & 187.81 \\
\hline 18 & {$\left[M-\left(b_{x}\right)-(N H 3)-\operatorname{ion}(1)\right]^{+}$} & 790.69 & 846.75 & 720.61 & 776.67 & 733.67 & 789.73 & 663.59 & 719.65 \\
\hline 18 & {$\left[M-\left(b_{x}\right)-(N H 3)-\operatorname{ion}(1)\right]^{2+}$} & 395.85 & 423.87 & 360.81 & 388.84 & 367.33 & 395.37 & 332.30 & 360.33 \\
\hline 18 & {$\left[M-\left(b_{x}\right)-(N H 3)-\operatorname{ion}(1)\right]^{3+}$} & 264.23 & 282.92 & 240.87 & 259.56 & 245.23 & 263.91 & 221.87 & 240.55 \\
\hline
\end{tabular}


Table 2. Precursor ions and product ions observed during MS/MS analysis of $[\mathrm{M}+\mathrm{H}]{ }^{3+}$ ions of the peptide modified gemini surfactants with mono-terminal lysine moiety.

\begin{tabular}{|c|c|c|c|c|}
\hline & Gemini surfactants & $16-7 N\left(G-C_{11}-K\right)-16$ & $12-7 N\left(G-C_{6}-K\right)-12$ & $16-7 N\left(G-C_{6}-K\right)-16$ \\
\hline & & $m / z$ & $m / z$ & $m / z$ \\
\hline & Precursor ions & 335.6693 & 274.9356 & 312.3098 \\
\hline Ion \# & Product ions & $m / z$ & $m / z$ & $m / z$ \\
\hline A & {$\left[\mathrm{M}-\mathrm{C}_{6} \mathrm{H}_{13} \mathrm{~N}_{2} \mathrm{O}\right]^{2+}$} & 438.95 & 347.85 & 403.91 \\
\hline B & {$\left[\mathrm{M}-\mathrm{NH}_{3}\right]^{3+}$} & 329.99 & 269.26 & 306.63 \\
\hline $\mathbf{b}_{1}$ & $\mathrm{C}_{6} \mathrm{H}_{13} \mathrm{~N}_{2} \mathrm{O}$ & 129.10 & 129.10 & 129.10 \\
\hline 1 & Dimethylalkenammonium & 270.31 & 214.25 & 270.31 \\
\hline 2 & {$\left[M-\left(b_{1}\right)-\operatorname{ion}(1)\right]^{+}$} & 607.59 & 481.44 & 537.51 \\
\hline 2 & {$\left[M-\left(b_{1}\right)-\operatorname{ion}(1)\right]^{2+}$} & 304.30 & 241.23 & 269.26 \\
\hline 3 & {$\left[M-\left(b_{1}\right)-2 \operatorname{ion}(1)\right]^{+}$} & 338.28 & 268.20 & 268.20 \\
\hline 3 & {$\left[M-\left(b_{1}\right)-2 \operatorname{ion}(1)\right]^{2+}$} & 169.64 & 134.60 & 134.60 \\
\hline 4 & {$\left[\mathrm{M}-\left(\mathrm{NH}_{3}\right)-\operatorname{ion}(1)\right]^{3+}$} & 240.22 & 198.18 & 216.86 \\
\hline 5 & {$\left[\mathrm{M}-\left(\mathrm{NH}_{3}\right)-2 \operatorname{ion}(1)\right]^{2+}$} & 225.18 & 190.14 & 190.14 \\
\hline
\end{tabular}



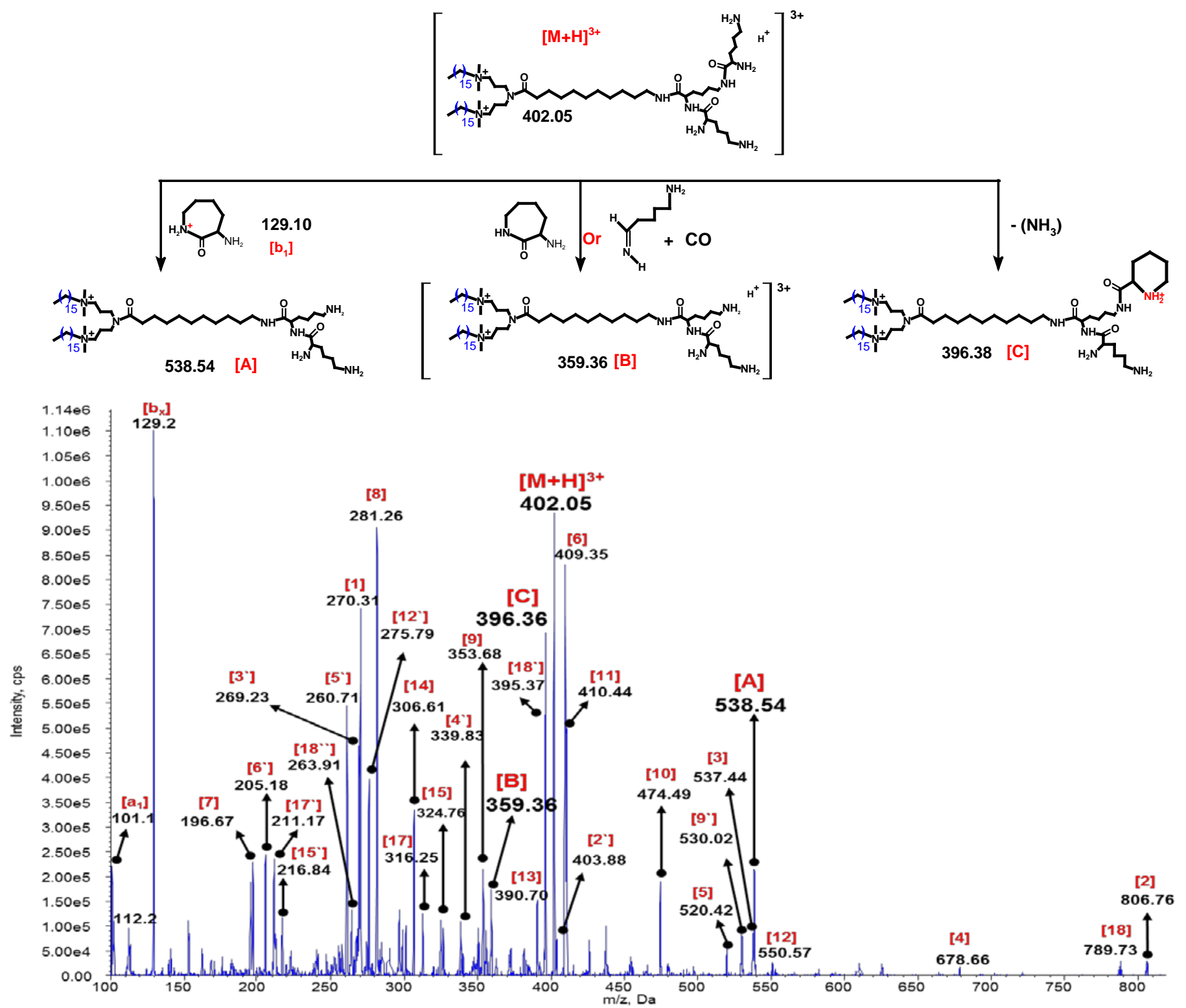

Figure 2. The ESI-QqLIT-MS/MS spectrum of $16-7 \mathrm{~N}\left(\mathrm{C}_{11}-\mathrm{K}_{3}\right)-16$ as a representative example of gemini surfactants with tri-terminal lysine moieties. Ions were labelled as designated in Figures 5-7. Strcture of the three initial product ions are shown as an insert (top). 


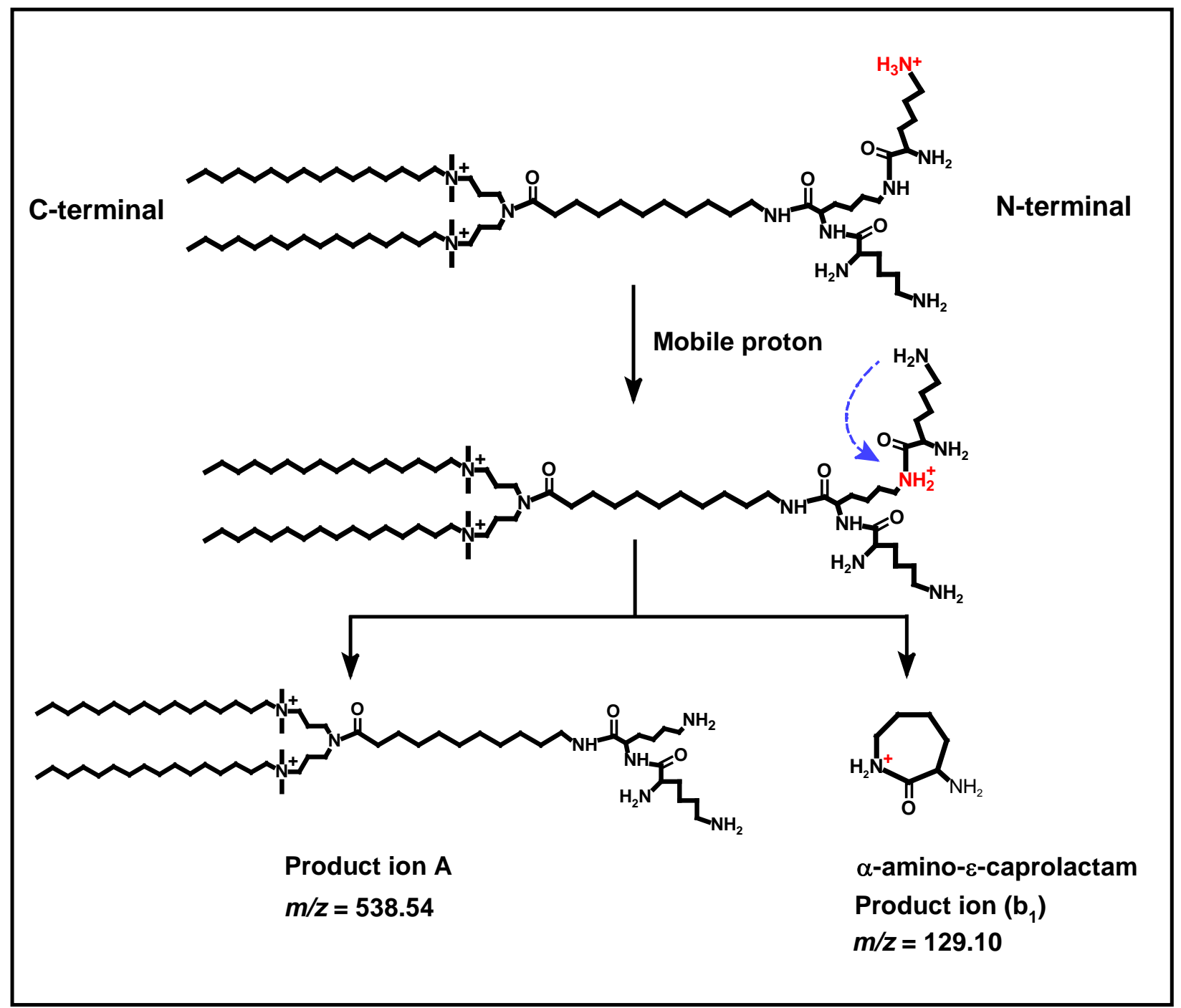

Figure 3. The proposed mechanism for the formation of product ion $(A)$ and $\left(b_{1}\right)$ : amide bond cleavage initiated by lysine side chain 


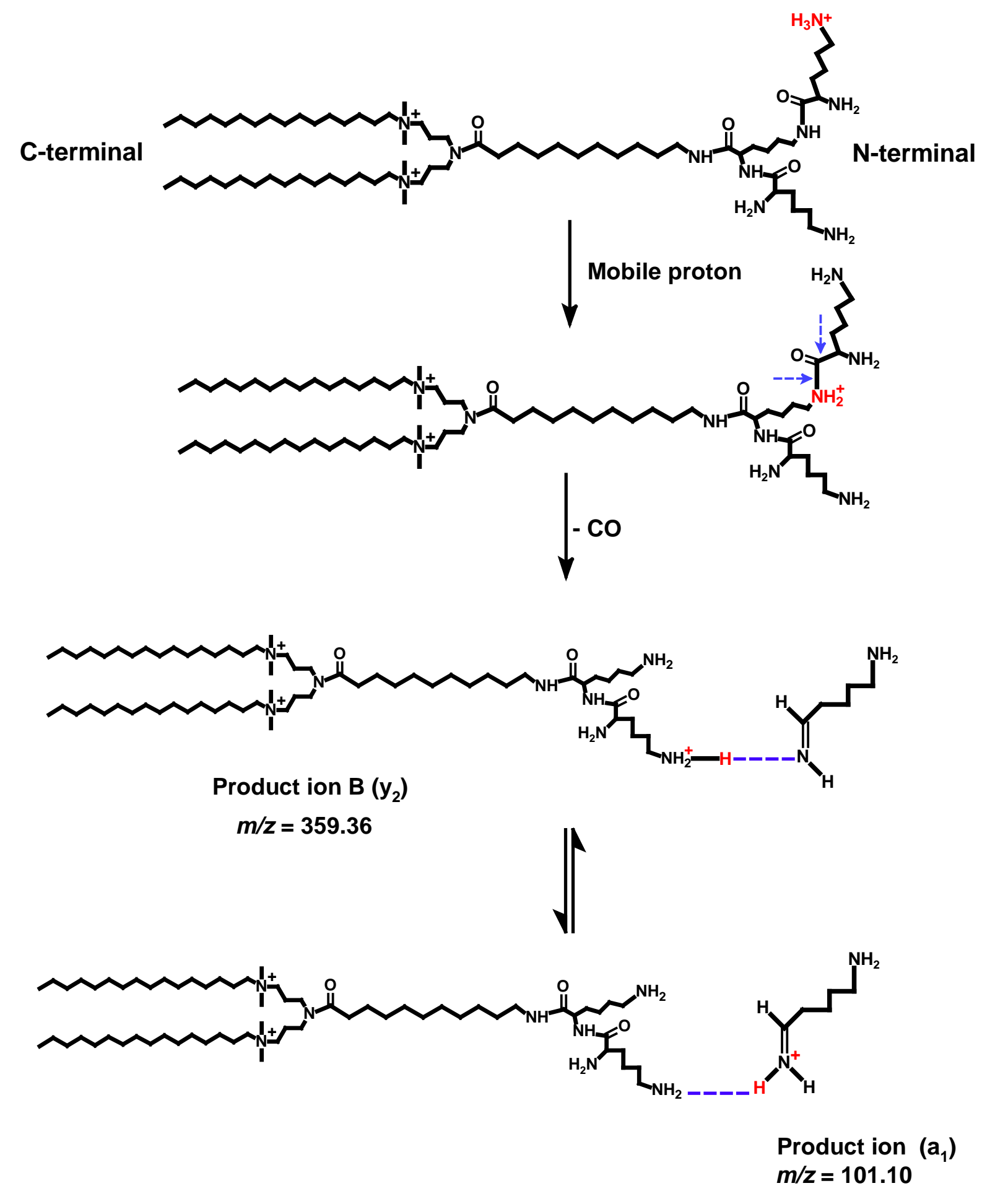

Figure 4. The proposed mechanism for the formation of product ion (B) and $\left(a_{1}\right)$ : cleavage of $\mathrm{C} \alpha-\mathrm{C}_{\text {amide }}$ bond through $\mathrm{a}_{\mathrm{x}}-\mathrm{y}_{\mathrm{x}}$ fragmentation pathway. 


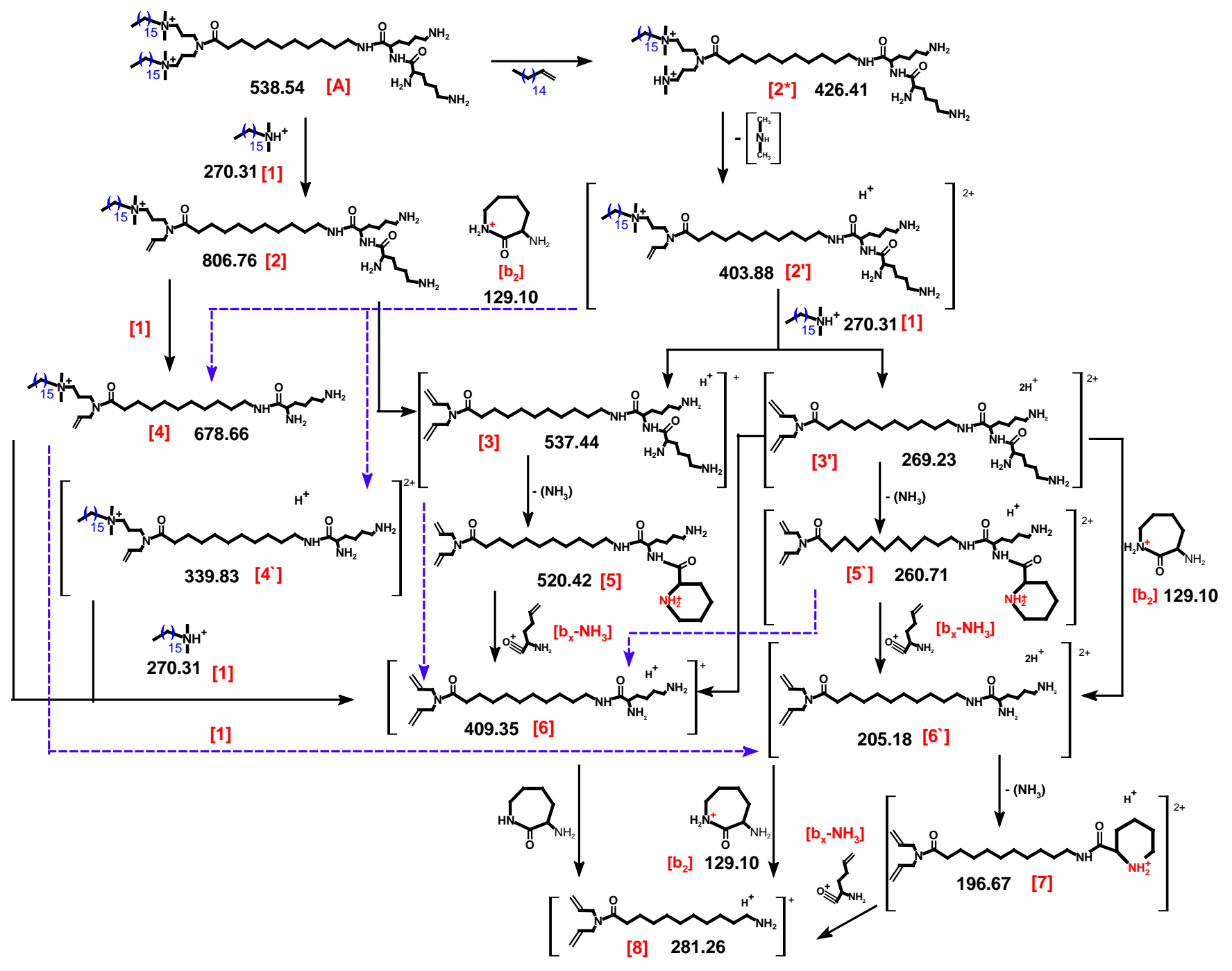

Figure 5. Proposed MS/MS product ions generated form product ion (A) at $\mathrm{m} / \mathrm{z} 538.54$ of 16 $7 \mathrm{~N}(\mathrm{C} 11-\mathrm{K} 3)-16$ gemini surfactant. Product ion $2 *$ is an intermediate ion. 


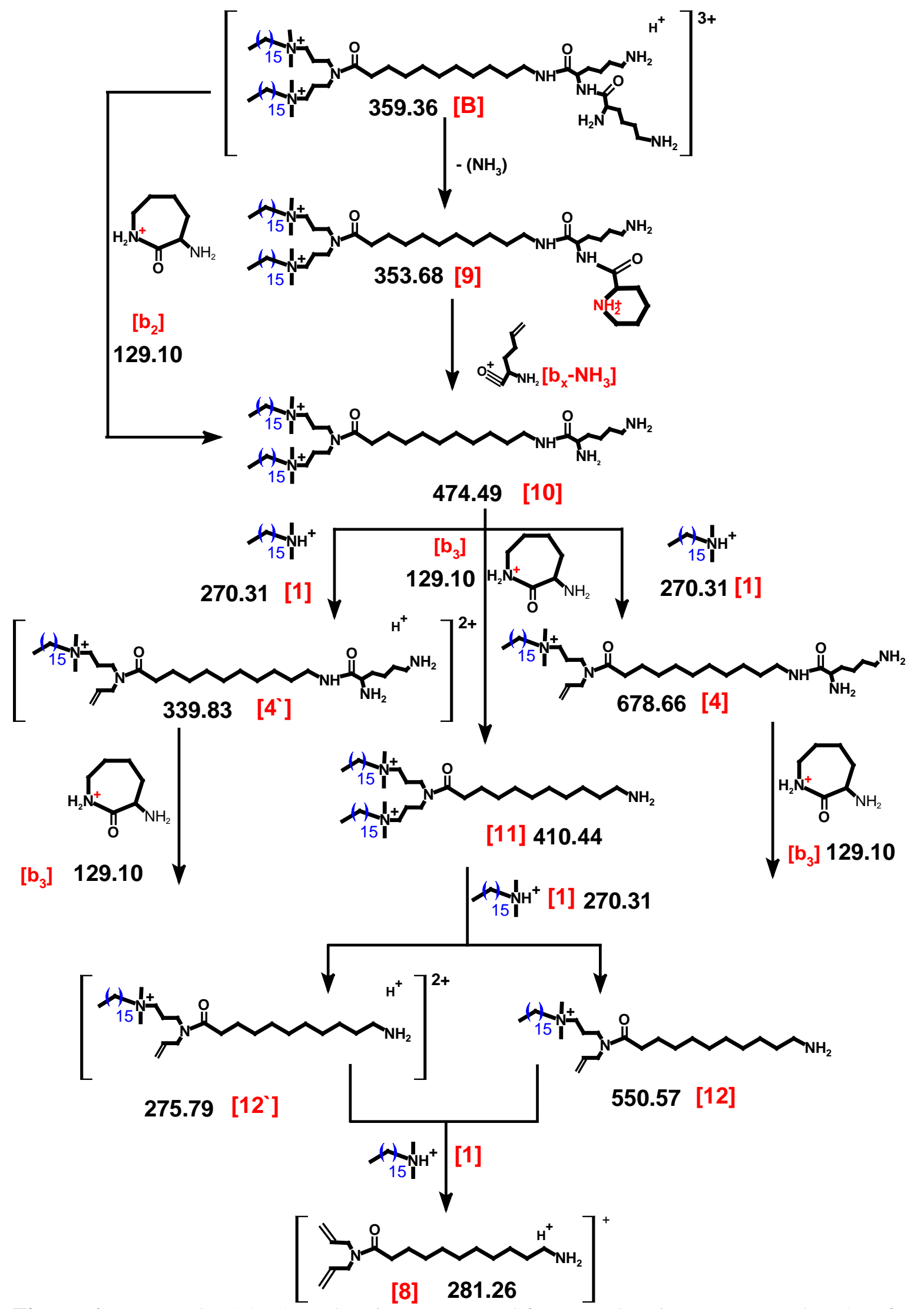

Figure 6. Proposed MS/MS product ions generated form product ion (B) at $m / z 359.36$ of 167N(C11-K3)-16 gemini surfactant. 


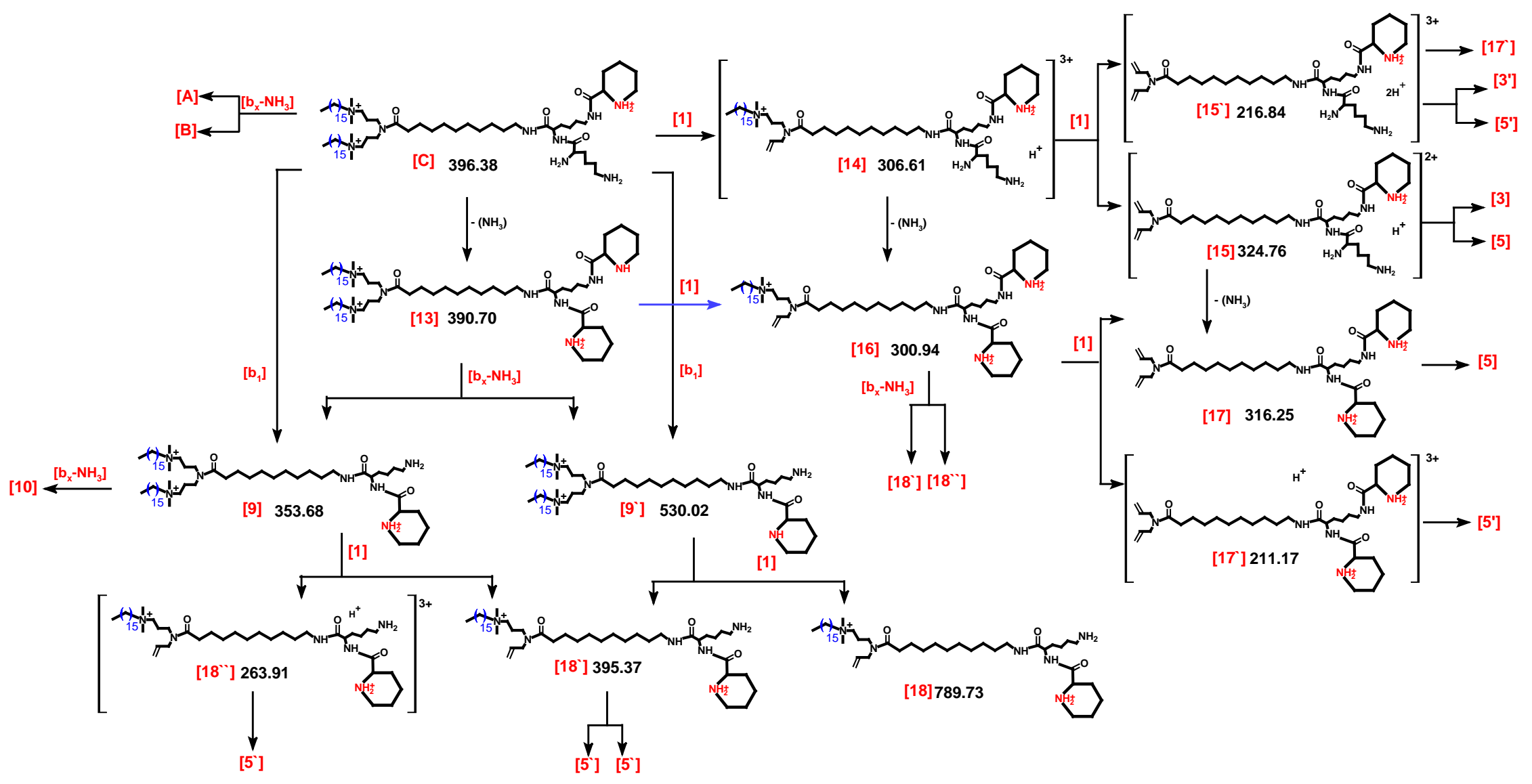

Figure 7. Proposed MS/MS product ions generated form product ion (C) at m/z 396.38 of 16-7N(C11-K3)-16 gemini surfactant. 


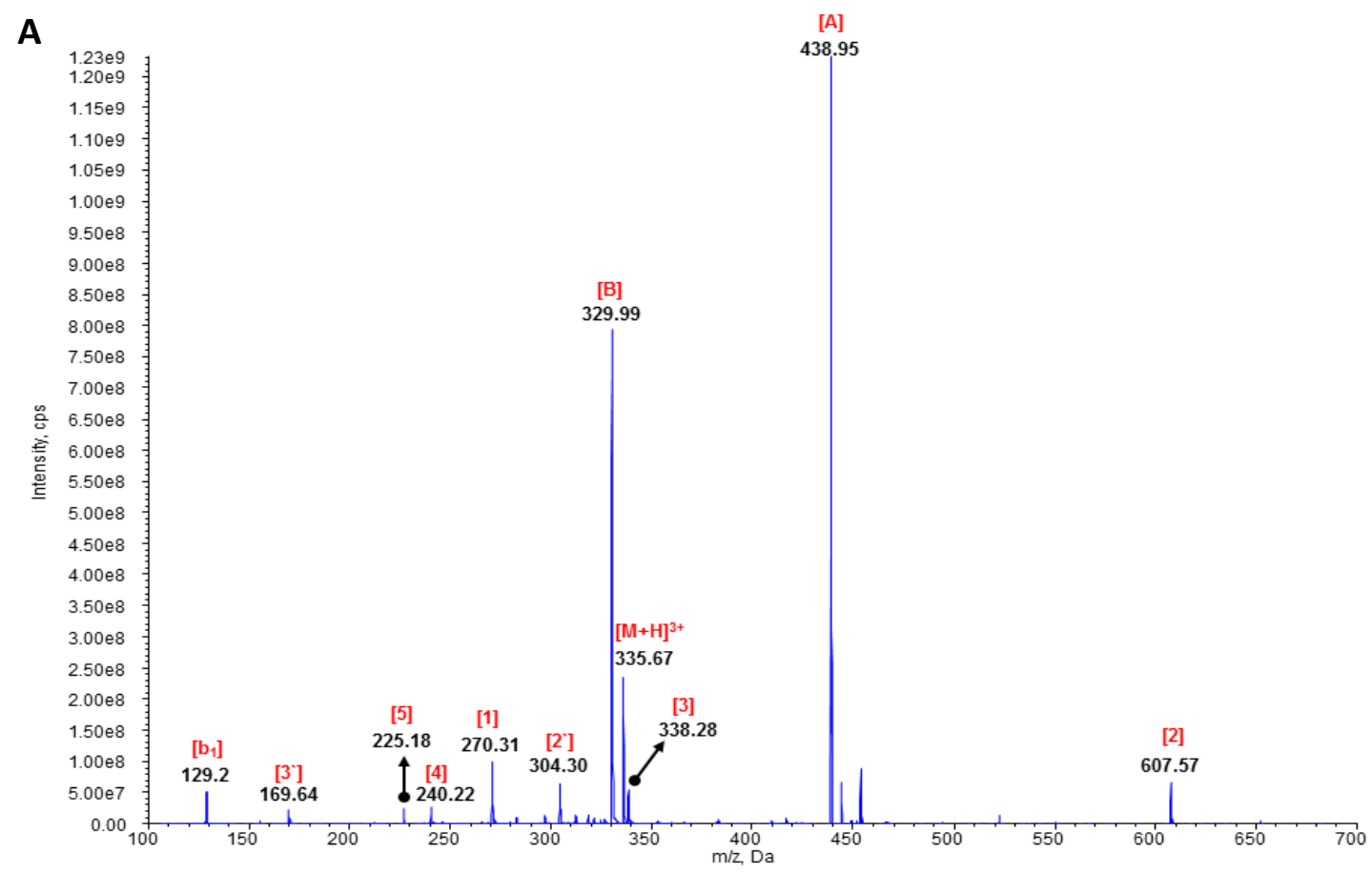

B
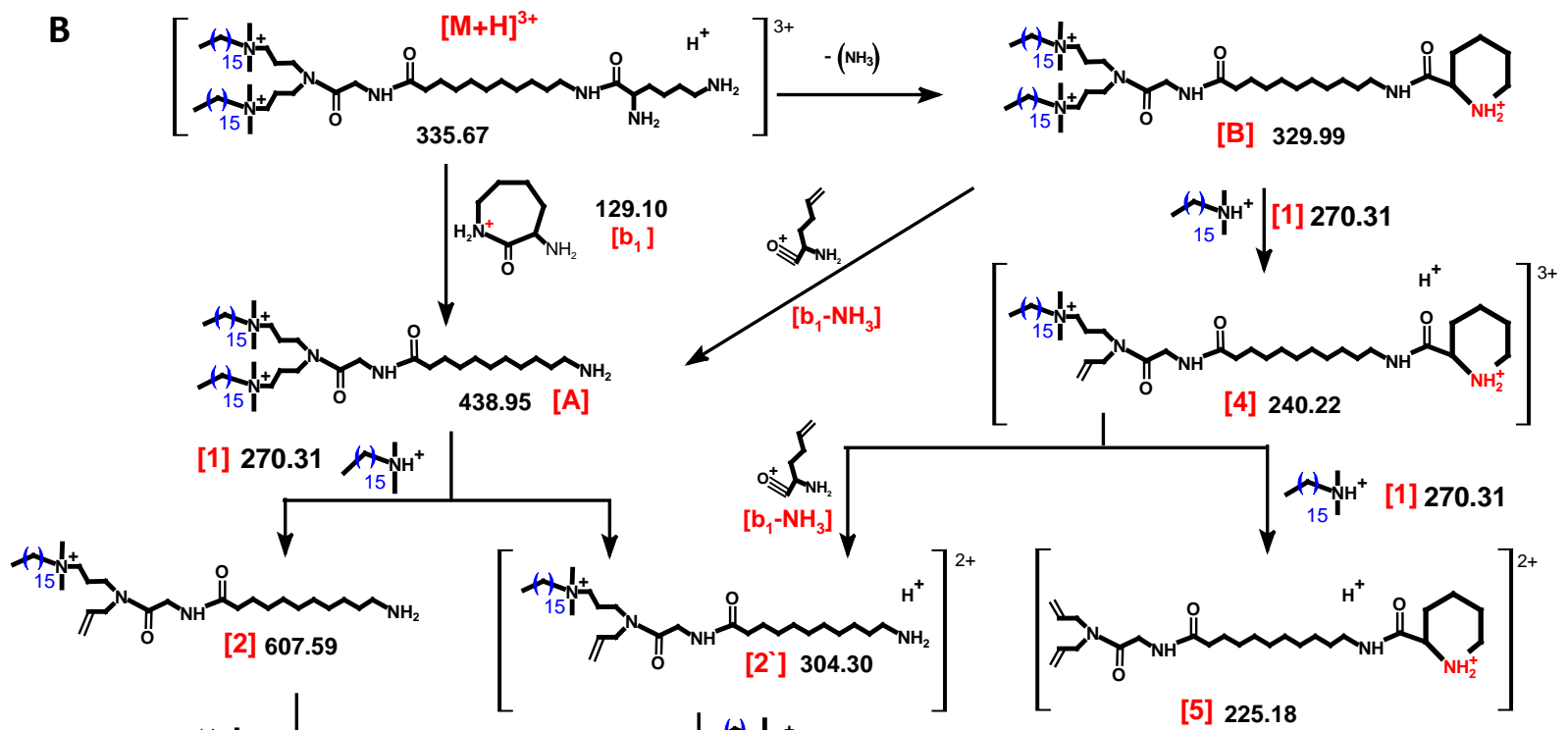

[1] $270.31 \mathrm{XIN}_{15 \mathrm{~N}^{+}}$

$\mathrm{XNH}_{15}^{\mathrm{N} \mathrm{N}^{+}} \mathbf{2 7 0 . 3 1}[1]$

[5] 225.18

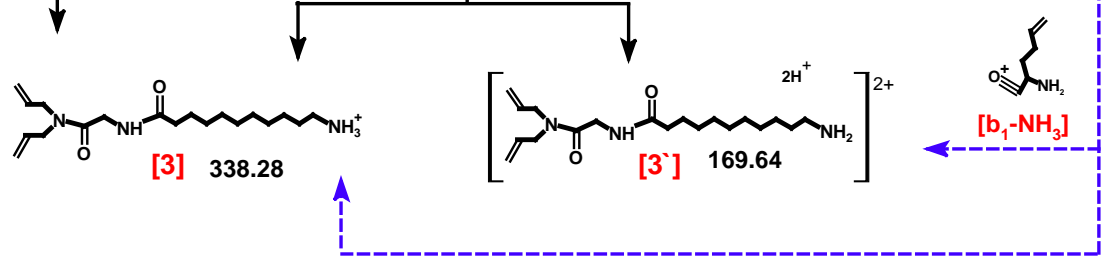

Figure 8. (A) The ESI-QqLIT MS/MS spectrum of $16-7 N\left(\mathrm{G}-\mathrm{C}_{11}-\mathrm{k}\right)-16$ as a representative example of gemini surfactants with mono-terminal lysine moiety and (B) the proposed MS/MS fragmentation pattern. 


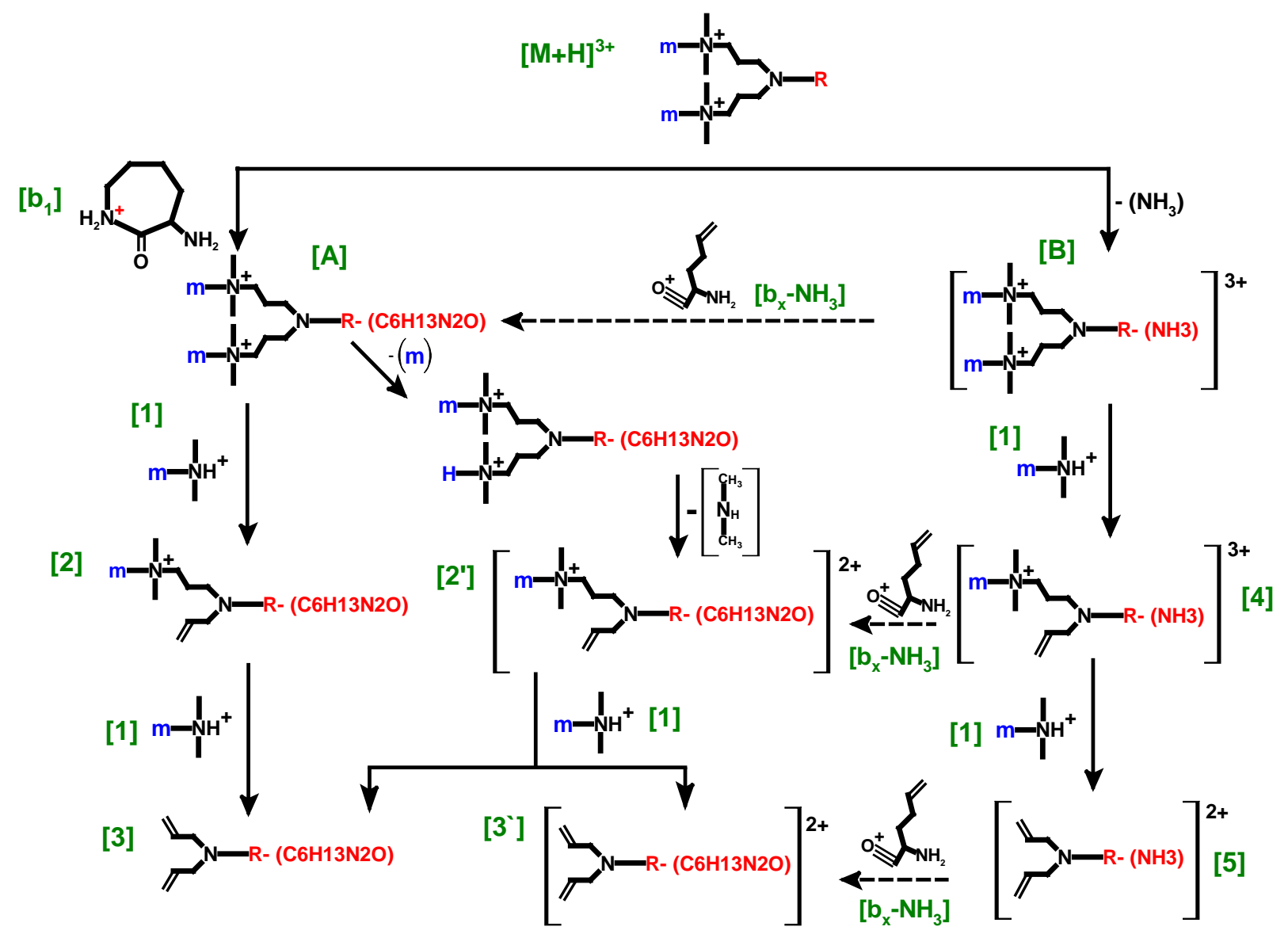

Figure 9. Universal MS/MS fragmentation pattern for peptide modified gemini surfactants. 


\section{References}

1. Jin, L., Zeng, X., Liu, M., Deng, Y., He, N.: Current progress in gene delivery technology based on chemical methods and nano-carriers. Theranostics. 4, 240-255 (2014)

2. Singh, J., Mohammed-Saied, W., Kaur, R., Badea, I.: Nanoparticles in Gene Therapy: From Design to Clinical Applications. Reviews in Nanoscience and Nanotechnology. 2, 275-299 (2013)

3. Ahmed, T., Kamel, A.O., Wettig, S.D.: Interactions between DNA and Gemini surfactant: impact on gene therapy: part I. Nanomedicine. (2016)

4. Elsabahy, M., Badea, I., Verrall, R., Donkuru, M., Foldvari, M.: Dicationic gemini nanoparticle design for gene therapy. Organic nanomaterials. Wiley. 509-528 (2014)

5. Menger, F.M., Littau, C.: Gemini-surfactants: synthesis and properties. Journal of the American Chemical Society. 113, 1451-1452 (1991)

6. Rosen, M.J., Tracy, D.J.: Gemini surfactants. Journal of Surfactants and Detergents. 1, 547-554 (1998)

7. Singh, J., Michel, D., Chitanda, J.M., Verrall, R.E., Badea, I.: Evaluation of cellular uptake and intracellular trafficking as determining factors of gene expression for amino acid-substituted gemini surfactant-based DNA nanoparticles. J Nanobiotechnology. 10, (2012)

8. Badea, I., Verrall, R., Baca-Estrada, M., Tikoo, S., Rosenberg, A., Kumar, P., et al.: In vivo cutaneous interferon- $\gamma$ gene delivery using novel dicationic (gemini) surfactantplasmid complexes. The journal of gene medicine. 7, 1200-1214 (2005)

9. Badea, I., Wettig, S., Verrall, R., Foldvari, M.: Topical non-invasive gene delivery using gemini nanoparticles in interferon- $\gamma$-deficient mice. European journal of pharmaceutics and biopharmaceutics. 65, 414-422 (2007)

10. Garcia, M.T., Kaczerewska, O., Ribosa, I., Brycki, B., Materna, P., Drgas, M.: Biodegradability and aquatic toxicity of quaternary ammonium-based gemini surfactants: Effect of the spacer on their ecological properties. Chemosphere. 154, 155-160 (2016)

11. Wasungu, L., Scarzello, M., van Dam, G., Molema, G., Wagenaar, A., Engberts, J.B., et al.: Transfection mediated by $\mathrm{pH}$-sensitive sugar-based gemini surfactants; potential for in vivo gene therapy applications. Journal of molecular medicine. 84, 774-784 (2006)

12. Kim, B.-K., Doh, K.-O., Bae, Y.-U., Seu, Y.-B.: Synthesis and optimization of cholesterol-based diquaternary ammonium gemini surfactant (chol-gs) as a new gene delivery vector. J. Microbiol. Biotechnol. 21, 93-99 (2011)

13. Pérez, L., Pinazo, A., Pons, R., Infante, M.: Gemini surfactants from natural amino acids. Advances in colloid and interface science. 205, 134-155 (2014)

14. Yang, P., Singh, J., Wettig, S., Foldvari, M., Verrall, R.E., Badea, I.: Enhanced gene expression in epithelial cells transfected with amino acid-substituted gemini nanoparticles. European Journal of Pharmaceutics and Biopharmaceutics. 75, 311-320 (2010)

15. Singh, J., Yang, P., Michel, D., E Verrall, R., Foldvari, M., Badea, I.: Amino AcidSubstituted Gemini Surfactant-Based Nanoparticles as Safe and Versatile Gene Delivery Agents. Current Drug Delivery. 8, 299-306 (2011)

16. Al-Dulaymi, M.A., Chitanda, J.M., Mohammed-Saeid, W., Araghi, H.Y., Verrall, R.E., Grochulski, P., et al.: Di-Peptide-Modified Gemini Surfactants as Gene Delivery Vectors: 
Exploring the Role of the Alkyl Tail in Their Physicochemical Behavior and Biological Activity. The AAPS journal. 1-14 (2016)

17. Singh, J., Michel, D., Getson, H.M., Chitanda, J.M., Verrall, R.E., Badea, I.: Development of amino acid substituted gemini surfactant-based mucoadhesive gene delivery systems for potential use as noninvasive vaginal genetic vaccination. Nanomedicine. 10, 405-417 (2015)

18. Mohammed-Saeid, W., Michel, D., El-Aneed, A., Verrall, R.E., Low, N.H., Badea, I.: Development of Lyophilized Gemini Surfactant-Based Gene Delivery Systems: Influence of Lyophilization on the Structure, Activity and Stability of the Lipoplexes. Journal of Pharmacy \& Pharmaceutical Sciences. 15, 548-567 (2012)

19. Aceña, J., Stampachiacchiere, S., Pérez, S., Barceló, D.: Advances in liquid chromatography-high-resolution mass spectrometry for quantitative and qualitative environmental analysis. Analytical and bioanalytical chemistry. 407, 6289-6299 (2015)

20. Lyubarskaya, Y., Kobayashi, K., Swann, P.: Application of mass spectrometry to facilitate advanced process controls of biopharmaceutical manufacture. Pharmaceutical Bioprocessing. 3, 313-321 (2015)

21. Lietz, C.B., Gemperline, E., Li, L.: Qualitative and quantitative mass spectrometry imaging of drugs and metabolites. Advanced drug delivery reviews. 65, 1074-1085 (2013)

22. Pacholarz, K.J., Garlish, R.A., Taylor, R.J., Barran, P.E.: Mass spectrometry based tools to investigate protein-ligand interactions for drug discovery. Chemical Society Reviews. 41, 4335-4355 (2012)

23. Buse, J., Badea, I., Verrall, R.E., El-Aneed, A.: Tandem mass spectrometric analysis of the novel gemini surfactant nanoparticle families G12-s and G18: 1-s. Spectroscopy Letters. 43, 447-457 (2010)

24. Buse, J., Badea, I., Verrall, R.E., El-Aneed, A.: Tandem mass spectrometric analysis of novel diquaternary ammonium gemini surfactants and their bromide adducts in electrospray-positive ion mode ionization. Journal of Mass Spectrometry. 46, 1060-1070 (2011)

25. Mohammed-Saeid, W., Buse, J., Badea, I., Verrall, R., El-Aneed, A.: Mass spectrometric analysis of amino acid/di-peptide modified gemini surfactants used as gene delivery agents: Establishment of a universal mass spectrometric fingerprint. International Journal of Mass Spectrometry. 309, 182-191 (2012)

26. Donkuru, M., Chitanda, J.M., Verrall, R.E., El-Aneed, A.: Multi-stage tandem mass spectrometric analysis of novel $\beta$-cyclodextrin-substituted and novel bis-pyridinium gemini surfactants designed as nanomedical drug delivery agents. Rapid Communications in Mass Spectrometry. 28, 757-772 (2014)

27. Buse, J., Badea, I., Verrall, R.E., El-Aneed, A.: A general liquid chromatography tandem mass spectrometry method for the quantitative determination of diquaternary ammonium gemini surfactant drug delivery agents in mouse keratinocytes' cellular lysate. Journal of Chromatography A. 1294, 98-105 (2013)

28. Buse J, P.R., Verrall RE, Badea I, Zhang H, Mulligan CC, Peru KM, Bailey J, Headley JV, El-Aneed A.*: The Development and assessment of high-throughput mass spectrometry-based methods for the quantification of a nanoparticle drug delivery agent in cellular lysate. Journal of Mass Spectrometry., (2014) 
29. Donkuru, M., Michel, D., Awad, H., Katselis, G., El-Aneed, A.: Hydrophilic interaction liquid chromatography-tandem mass spectrometry quantitative method for the cellular analysis of varying structures of gemini surfactants designed as nanomaterial drug carriers. Journal of Chromatography A. 1446, 114-124 (2016)

30. Mays Al-Dulaymi, Deborah Michel, Waleed Mohammed Saeid, Jackson Chitanda, Ronald Verrall, Pawel Grochulski, Anas El-Aneed, Ildiko Badea.: Novel peptidemodified gemini surfactants as gene carriers structure activity relashinship,physicochemical characterizations and mass spectrometric dissociation behaviour. AAPS Annual Meeting and Exhibitioned. Colorado, Denver, USA 2016.

31. Boyd, R., Somogyi, Á.: The mobile proton hypothesis in fragmentation of protonated peptides: a perspective. Journal of the American Society for Mass Spectrometry. 21, 1275-1278 (2010)

32. Wysocki, V.H., Tsaprailis, G., Smith, L.L., Breci, L.A.: Mobile and localized protons: a framework for understanding peptide dissociation. Journal of Mass Spectrometry. 35, 1399-1406 (2000)

33. Wysocki, V.H., Cheng, G., Zhang, Q., Herrmann, K.A., Beardsley, R.L., Hilderbrand, A.E.: Peptide Fragmentation Overview. (2006)

34. Paizs, B., Suhai, S.: Fragmentation pathways of protonated peptides. Mass spectrometry reviews. 24, 508-548 (2005)

35. Yalcin, T., Harrison, A.G.: Ion chemistry of protonated lysine derivatives. Journal of mass spectrometry. 31, 1237-1243 (1996)

36. Csonka, I.P., Paizs, B., Lendvay, G., Suhai, S.: Proton mobility and main fragmentation pathways of protonated lysylglycine. Rapid Communications in Mass Spectrometry. 15, 1457-1472 (2001)

37. Dookeran, N.N., Yalcin, T., Harrison, A.G.: Fragmentation reactions of protonatedamino acids. Journal of mass spectrometry. 31, 500-508 (1996)

38. Paizs, B., Schnölzer, M., Warnken, U., Suhai, S., Harrison, A.G.: Cleavage of the amide bond of protonated dipeptides. Physical Chemistry Chemical Physics. 6, 2691-2699 (2004)

39. Paizs, B., Suhai, S.: Theoretical study of the main fragmentation pathways for protonated glycylglycine. Rapid Communications in Mass Spectrometry. 15, 651-663 (2001)

40. Roepstorff, P., Fohlman, J.: Proposal for a Common Nomenclature for Sequence Ions in Mass-Spectra of Peptides. Biomed Mass Spectrom. 11, 601-601 (1984) 